\title{
A TIME RESOLVED IR LASER PHOTOLYSIS-LASER INDUCED FLUORESCENCE STUDY OF THE OH/METHANOL REACTION
}

\author{
JOSÉ M. RIVEROS* \\ Instituto de Química, Universidade de São Paulo, Caixa Postal 20780, São \\ Paulo, Brazil, CEP 01498-970 \\ LUIS GILBERTO BARRETA \\ Instituto de Estudos Avançados, Centro Técnico Aeroespacial, Sao José dos \\ Campos, Brazil
}

(Received 12th January 1994)

\begin{abstract}
The reaction of hydroxyl radicals (OH and OD) generated by infrared multiphoton dissociation of different isotopomers of methanol were studied in the presence of variable amounts of Ar buffer gas. The disappearance of the $\mathrm{OH}$, or $\mathrm{OD}$, radicals in the presence of the parent methanol was followed by laser induced fluorescence at $310 \mathrm{~nm}$. Comparison of the rate constants obtained from these experiments reveal good agreement with observed isotope effects observed by other authors but suggest that the reactions occurs at higher temperatures than the macroscopic bulk temperature of the sample.
\end{abstract}

KEY WORDS: OH-methanol reaction; LiF.

The increasing appeal of alternative fuels has been responsible for a lively interest in the elucidation of the gas phase oxidation of alcohols..$^{1-3}$ One of the key steps in the mechanism involves the hydrogen atom abstraction promoted by the attack of a hydroxyl radical on these substrates. Because such elementary reactions are deemed to play a significant role in combustion and atmospheric chemistry, the literature has witnessed a variety of experimental techniques applied to the kinetic characterization of $\mathrm{OH}$ reactions in the gas phase. ${ }^{4}$

Pulsed infrared lasers have been used to generate transient species by multiphoton dissociation (MPD) processes and their application to combustion related reactions has been demonstrated in a few cases. ${ }^{5-7}$ Our own laboratory has explored the combination of pulsed $\mathrm{CO}_{2}$ lasers and time resolved emission techniques to mimic combustion processes in alcohols. ${ }^{8-13}$ Our work has shown that electronically excited $\mathrm{OH}$ radicals, generated by multiphoton excitation (MPE) of methanol and ethanol 
(1 to 10 Torr pressure range), react with simple substrates under these condition typically with rate constants slower than the radiative lifetime. ${ }^{14}$

This paper reports an investigation of the reactions of electronically ground state $\mathrm{OH}$ (and OD) with several isotopic variations of methanol by IR laser photolysislaser induced fluorescence. The formation and reaction of these radicals near the focal region of the IR laser can involve gas dynamic processes bearing some resemblance to the turbulent regime characteristic in combustion processes of practical interest.

The reaction of $\mathrm{OH}$ with methanol is a good test case to probe possible nonequilibrium effects observed in kinetic processes under MPE. The room temperature rate constant is believed to be well established ${ }^{15-23}$ although discrepancies remain at large regarding the temperature dependence of the rate constant. ${ }^{18-23}$ An important feature of the $\mathrm{OH} /$ alcohol reactions is the fact that several competitive channels can contribute to the general reaction. For methanol, abstraction of a hydrogen bonded to carbon (reaction 1a) is the preferred pathway at room temperature in the gas phase (around $85 \%$ ) and in aqueous solutions (of the order of 93\%). ${ }^{24}$

$$
\begin{gathered}
\cdot \mathrm{OH}+\mathrm{CH}_{3} \mathrm{OH} \rightarrow \cdot \mathrm{CH}_{2} \mathrm{OH}+\mathrm{H}_{2} \mathrm{O} \\
\mathrm{H} \rightarrow \mathrm{CH}_{3} \mathrm{O} \cdot+\mathrm{H}_{2} \mathrm{O}
\end{gathered}
$$

The contribution of reaction (1b) rises with temperature but an accurate determination of the branching ratio at different temperatures has proven to be a formidable task. ${ }^{18,19}$ Different isotopic variations of reaction (1) have also been explored ${ }^{20,22,23}$ and can provide an indirect view of the branching ratio and reaction mechanism. The partition of radical products under combustion conditions is extremely important in modeling studies because of the different subsequent chemistry of $\mathrm{CH}_{2} \mathrm{OH}$ and $\mathrm{CH}_{3} \mathrm{O}$.

\section{EXPERIMENTAL}

Experiments were carried out in a cylindrical stainless steel cell, $10 \mathrm{~cm}$ in length and $1.5 \mathrm{~cm}$ in diameter. Methanol was photolyzed with a pulsed TEA $\mathrm{CO}_{2}$ laser tightly focused in the center of the cell to an area with an estimated radius of $0.016 \mathrm{~cm}$. The laser was operated at a repetition rate of $3 \mathrm{~Hz}$ and the energy was maintained at $0.4 \mathrm{~J}$ per pulse. The laser pulse exhibits a $70 \mathrm{~ns}$ spike (containing $70 \%$ of the energy) and a long tail stretching to $1 \mu \mathrm{s}$. The $\mathrm{OH}$ radicals were produced by irradiation of methanol with the 9P22 laser line, while OD radicals were obtained from the deuterated compounds with the 10P20 line.

The nascent $\cdot \mathrm{OH}$, (or -OD) radicals were probed by laser induced fluorescence with a Lambda Physik XeCl excimer laser. This laser was operated at $308 \mathrm{~nm}$ with an approximate spectral bandwith of $2 \mathrm{~nm}$ allowing for the excitation of several of the low rotational Q-branch transitions of the $0-0$ band of the $A^{2} \Sigma^{+}-X^{2} \Pi_{i}$ electronic transition of $\mathrm{OH},{ }^{25}$ and several of the $\mathrm{Q}$ and $\mathrm{R}$-branch transitions of rotational numbers ranging from 10 to 25 for the same band of the OD radical. ${ }^{26}$ 


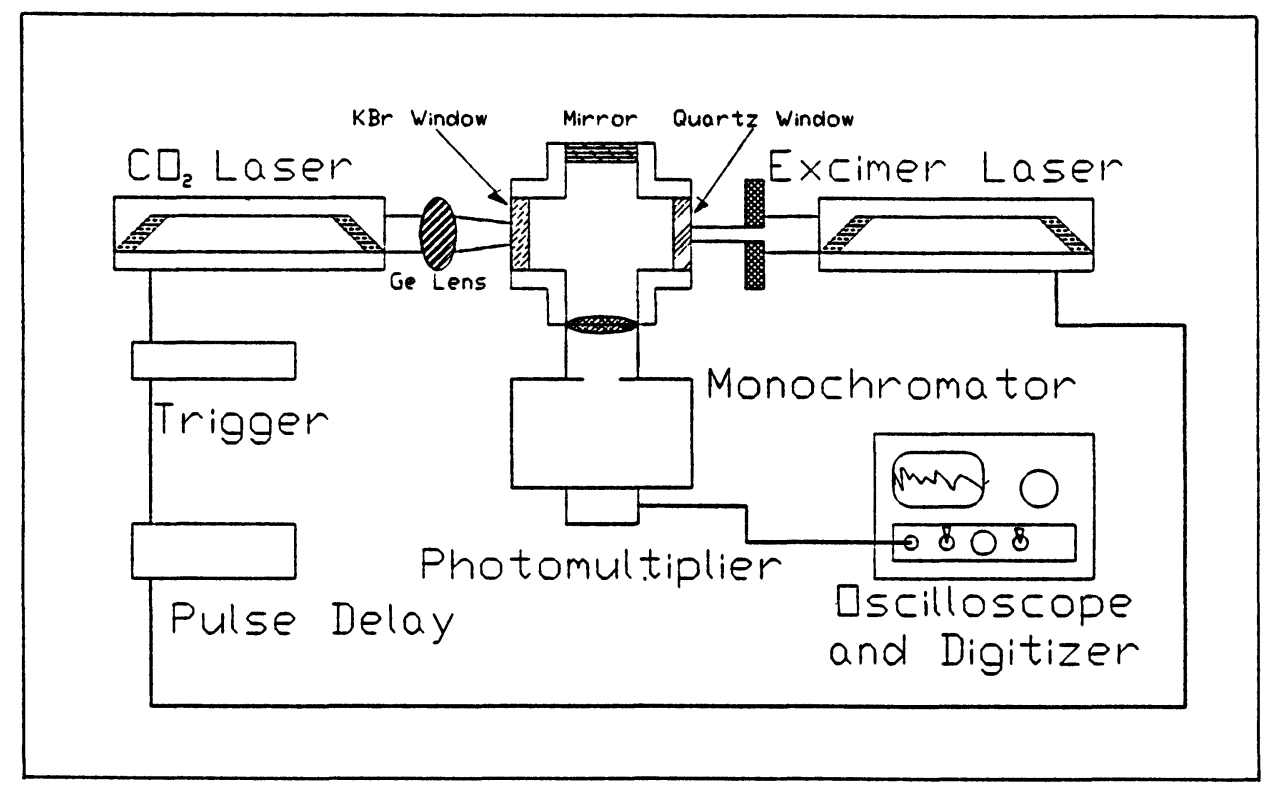

Figure 1 Experimental setup of the IRMPD-LIF studies.

The lasers in our experiments were used in the coaxial arrangement shown in Figure 1. The excimer laser was triggered by a homemade variable pulse delay generator with a $20 \mathrm{~ns}$ jitter. An iris $0.2 \mathrm{~cm}$ in diameter was used to collimate the beam of the excimer.

Florescence was collected at right angles to the laser beams through a monochromator set at $309.8 \mathrm{~nm}$ with the slits narrowed to a bandwidth of $0.3 \mathrm{~nm}$. This was necessary to reduce the effect of scattered light from the probe laser. This bandwidth allows for detection of the $\mathrm{OH}$ fluorescence from the $\mathrm{P}_{1}(4)$ and $\mathrm{Q}_{2}(8)$ rotational transitions of the $0-0$ band, while for the OD radical it samples a larger number of rotational transitions corresponding to the $P_{1}(9), P_{2}(7), Q_{2}(14), Q_{1}(16)$, $R_{2}(27)$ and $R_{1}(28)$. The observed OD fluorescence was much stronger than that of $\mathrm{OH}$ in our experiment.

The fluorescence selected by the monochromator was detected by a Hamamatsu photomultiplier (Model 106) operated at $800 \mathrm{~V}$. The signal of the photomultiplier was processed by a Tektronix digitizer and oscilloscope, Model 7D20. The time resolved fluorescence signal was recorded starting at delay times of at least $2.5 \mu \mathrm{s}$. This effectively reduces the background noise from electronically excited $\mathrm{OH}$ radicals $^{13}$ and minimizes possible contributions from radical-radical reactions, or high local temperatures, at the focal point of the $\mathrm{CO}_{2}$ laser.

Reagent grade methanol was used in all the experiments. The isotopomers, $\mathrm{CH}_{3} \mathrm{OD}$, $\mathrm{CD}_{3} \mathrm{OD}, \mathrm{CD}_{3} \mathrm{OH}$, were obtained from MD Isotopes with a stated D content higher than $99.5 \%$. Experiments involving $\mathrm{CH}_{3} \mathrm{OD}$ and $\mathrm{CD}_{3} \mathrm{OD}$ required extensive conditioning of the cell. Several cycles of baking and pumping of the cell in the presence 
of saturated $\mathrm{D}_{2} \mathrm{O}$ vapor were repeated over a period of 24 hours. No significant changes were noticeable in the rate constants after this procedure.

Experiments were carried out at variable partial pressures of the alcohols $(0.5$ to 8 Torr) diluted in Ar pressures up to 50 Torr. The best LIF signals were obtained at the lower partial pressures of the alcohols and at total pressures of 5 to 10 Torr. The cell was operated either under static or flow conditions. The latter experiments proved to be less reproducible and difficulty was experienced in maintaining a reliable partial pressure of the alcohol vapor in the presence of excess Ar. The data reported in this paper have been collected primarily in a semi-static system with discrete points measured at variable laser delay times by suitable adjustment of the variable pulse delay generator. Each point represents the average of 32 shots. Possible depletion of the sample was checked by periodically remeasuring the LIF signal of the first point of the curve and normalizing the signals when necessary. Variations of the initial point never exceeded $10 \%$. Runs were carried out from short to long delay times, and vice versa, in order to check for any systematic errors.

\section{Results and Discussion}

The $\cdot \mathrm{OH}$ (or $\cdot \mathrm{OD}$ ) radicals are produced via the well known MPD of methanol (or deuterated isotopomer), ${ }^{27}$

$$
\mathrm{CH}_{3} \mathrm{OH}+\mathrm{nhv}_{\mathrm{IR}} \rightarrow \cdot \mathrm{OH}+\cdot \mathrm{CH}_{3}
$$

The collissionless process has been measured to yield rotationally hot hydroxyl radicals with a mild excess of translation energy. ${ }^{28,29}$ Furthermore, the rotational temperature of the $\mathrm{OH}$ radical has been estimated to reach $400 \mathrm{~K}$ after $1.5 \mu \mathrm{s}$ in $90 \mathrm{mTorr}$ of methanol. ${ }^{28}$ The actual energy distribution of the radicals at the methanol pressures used in our experiments is unknown..$^{30}$ It is to be emphasized that in the pressure range used in our work modulation of the multiphoton excitation process by collisions is very important since rotational hole filling by collisions is very effective in enhancing multiphoton absorption in methanol. On the other hand, the long tail of the $\mathrm{CO}_{2}$ laser pulse can act as a very effective heating source of methanol molecules.

The time resolved LIF signal of a typical experiment is shown in Figure 2. The data points can be fitted smoothly in all cases by a single exponential decay curve. Disappearance of the $\mathrm{OH}$ radicals can arise from a combination of chemical reactions and diffusion out of the area probed by the excimer laser, or sampled by the detection system. A simple diffusion model yields an estimated upper limit of $100 \mu \mathrm{s}$ at 5 Torr for the average diffusion time from the area probed by the laser. This estimate is based on the diffusion coefficient obtained for $\mathrm{OH}$ in the presence of methanol. ${ }^{28}$ Since the half times for $\mathrm{OH}$ and OD decay are much faster than $100 \mu \mathrm{s}$, the disappearance of the $\mathrm{OH}$ radicals must be primarily related to chemical reactions.

The possibility that our kinetic curves for the disappearance of the $\mathrm{OH}$ and $\mathrm{OD}$ radicals also contain contributions from rotational relaxation needs to be considered carefully since our experimental setup samples only a small fraction (and a different 


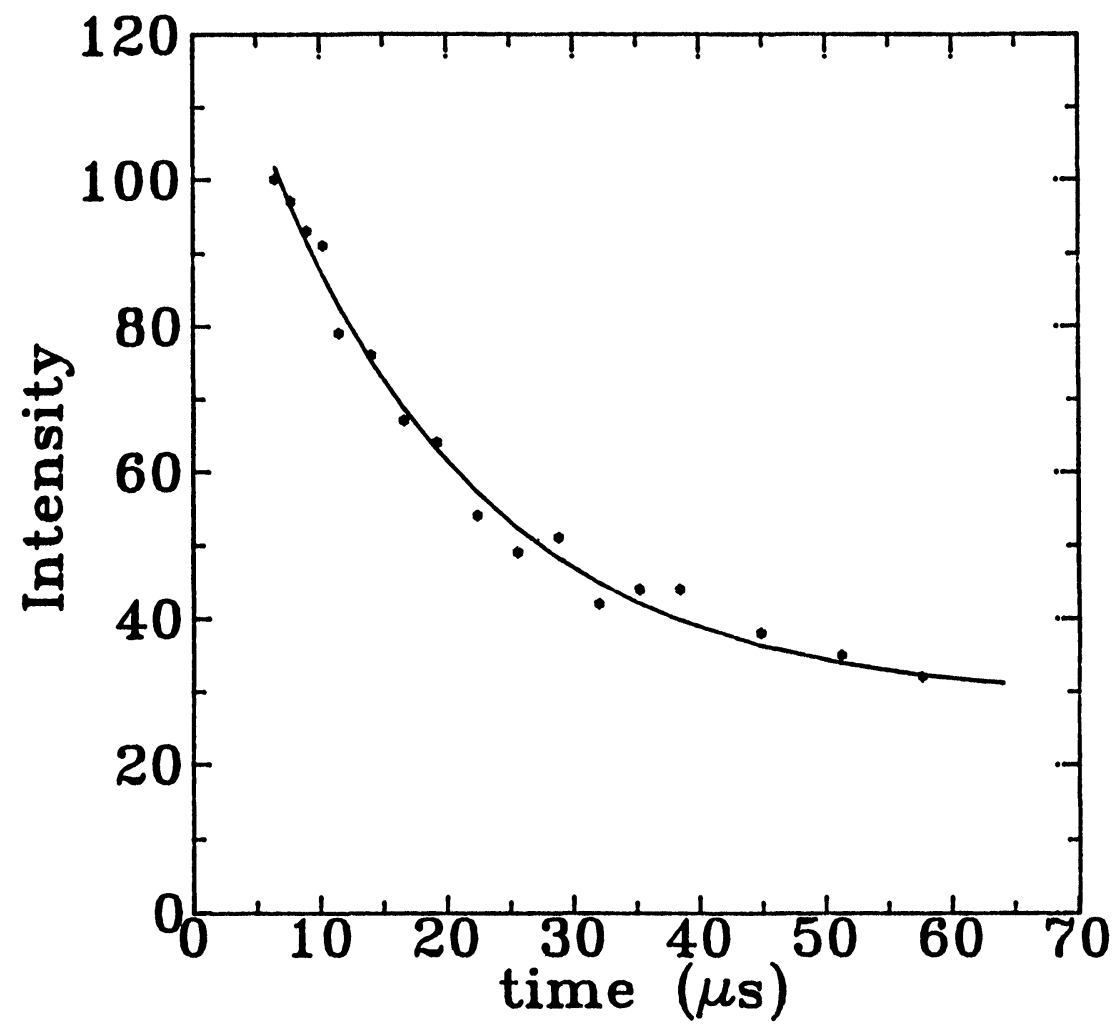

Figure 2 LIF signal (in arbitrary units) of the $\mathrm{OH}$ radical as a function of delay time of the excimer laser for an experiment carried out at 1 Torr of $\mathrm{CH}_{3} \mathrm{OH}$ and 4 Torr of Ar. The full line represents the best fitting by a single exponential. The remaining signal at long delay times corresponds to the background noise.

one) of the rovibronic transitions of $\mathrm{OH}$ and $\mathrm{OD}$. The early work of Guillory ${ }^{27}$ reveals that the rotational level populations achieve steady state at approximately $2 \mu \mathrm{s}$ after onset at methanol pressures of 90 mTorr. Since our experiments are carried out typically at 50 to 500 times larger total pressures, rotational relaxation by R-T energy transfer with the bath molecules must achieve steady state at times considerably shorter than our initial time for data collection $(2.5 \mu \mathrm{s})$. Additional rotational relaxation at longer times associated with complete thermalization of the system is discussed below in conjunction with temperature effects.

Experiments carried out at different partial pressure of methanol, but at constant total pressure (by addition of Ar), yield pseudo first order rate constants that scale with the methanol pressure. Typical results are shown in Figures 3 and 4 as plots of these apparent rate constants ( $\mathrm{K}$ ) as a function of the partial pressure of methanol. The error bars in the graphs represent the result of 8 different determinations. These graphs can be analyzed by a simple expression,

$$
\mathrm{k}=\mathrm{k}_{\mathrm{OH}} \mathrm{N}_{\mathrm{CH}_{3} \mathrm{OH}}+\mathrm{k}_{\mathrm{diff}} \text {, }
$$


if diffusion is considered to be essentially constant at constant total pressures. A least square fitting of the data for the different species (similar to that presented in Figures 3 and 4) yields an average diffusion time of $55 \mu \mathrm{s}$. This value is consistent with our rough estimates.

The above equation ignores possible reactions of $\mathrm{OH}$ with other radicals or some of the final products of multiphoton dissociation in a semi-static system. Because data collection starts at delay times larger than the expected diffusion time from the $\mathrm{CO}_{2}$ laser focal area, the likelihood of radical-radical reactions is greatly minimized. On the other hand, reactions of $\mathrm{OH}$ with $\mathrm{CH}_{4}, \mathrm{C}_{2} \mathrm{H}_{4}, \mathrm{CO}$ and $\mathrm{C}_{2} \mathrm{H}_{2}$ (the final products in the MPD of methanol) must also be considered as minimal since methanol depletion, even in a completely static system, can be estimated to be less than $7 \%$ by comparison with the original data of Guillory. ${ }^{27}$ Furthermore, rate constants for the reactions of $\mathrm{OH}$ with these substrates are considerably smaller than that of the $\mathrm{OH} /$ methanol reaction. ${ }^{4}$ The revised rate constant for the $\mathrm{OH} / \mathrm{C}_{2} \mathrm{H}_{4}$ is particularly noteworthy since it is considerably lower than the previous reported values. ${ }^{32}$

Bimolecular rate constants, $\mathrm{k}_{\mathrm{OH}}$, can be obtained from slope of our graphs as shown in Table 1 by assuming a methanol bulk temperature of $298 \mathrm{~K}$. A comparison with

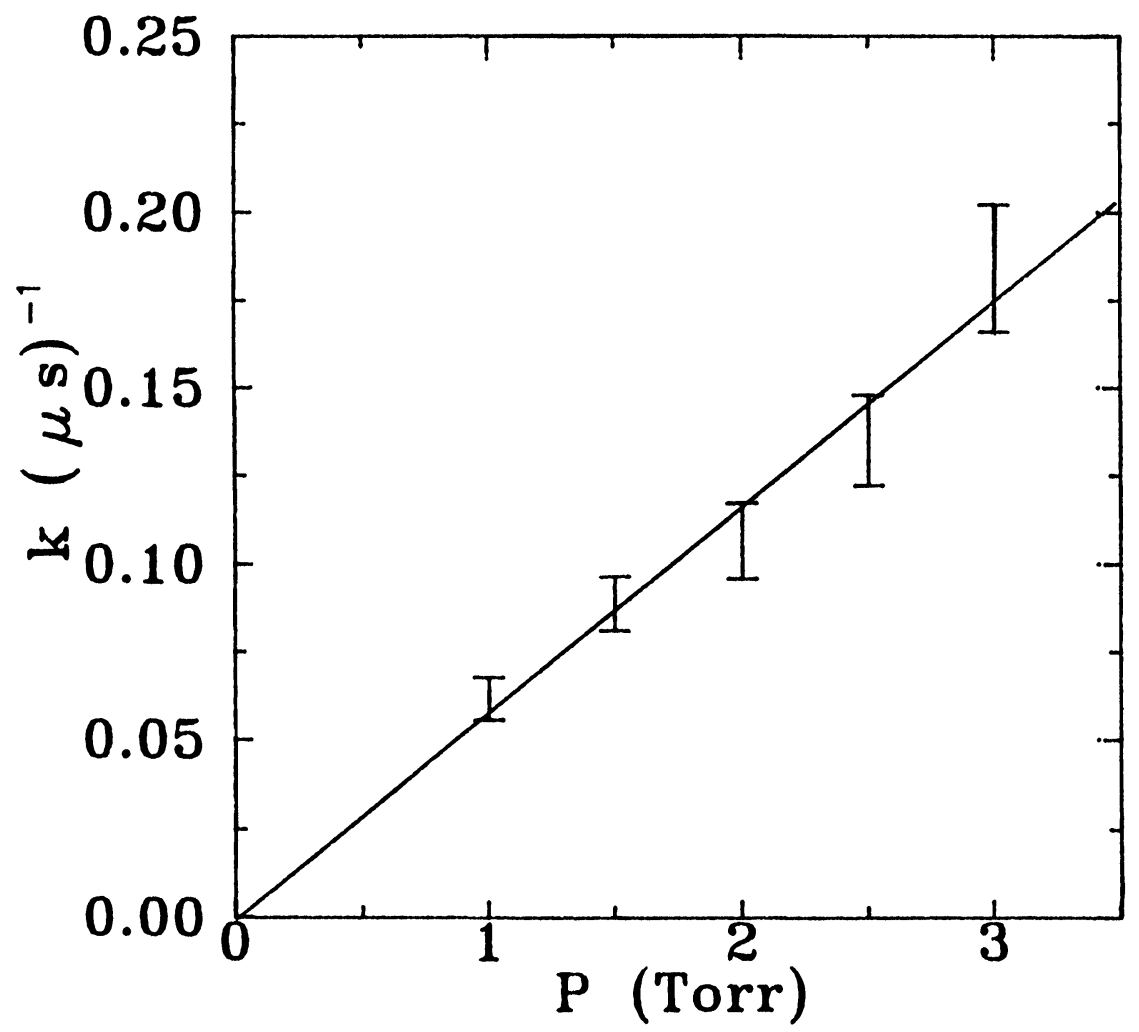

Figure 3 Pseudo first order rate constant as a function of $\mathrm{CH}_{3} \mathrm{OH}$ pressure. Error bars indicate the standard deviation of 8 measurements. 


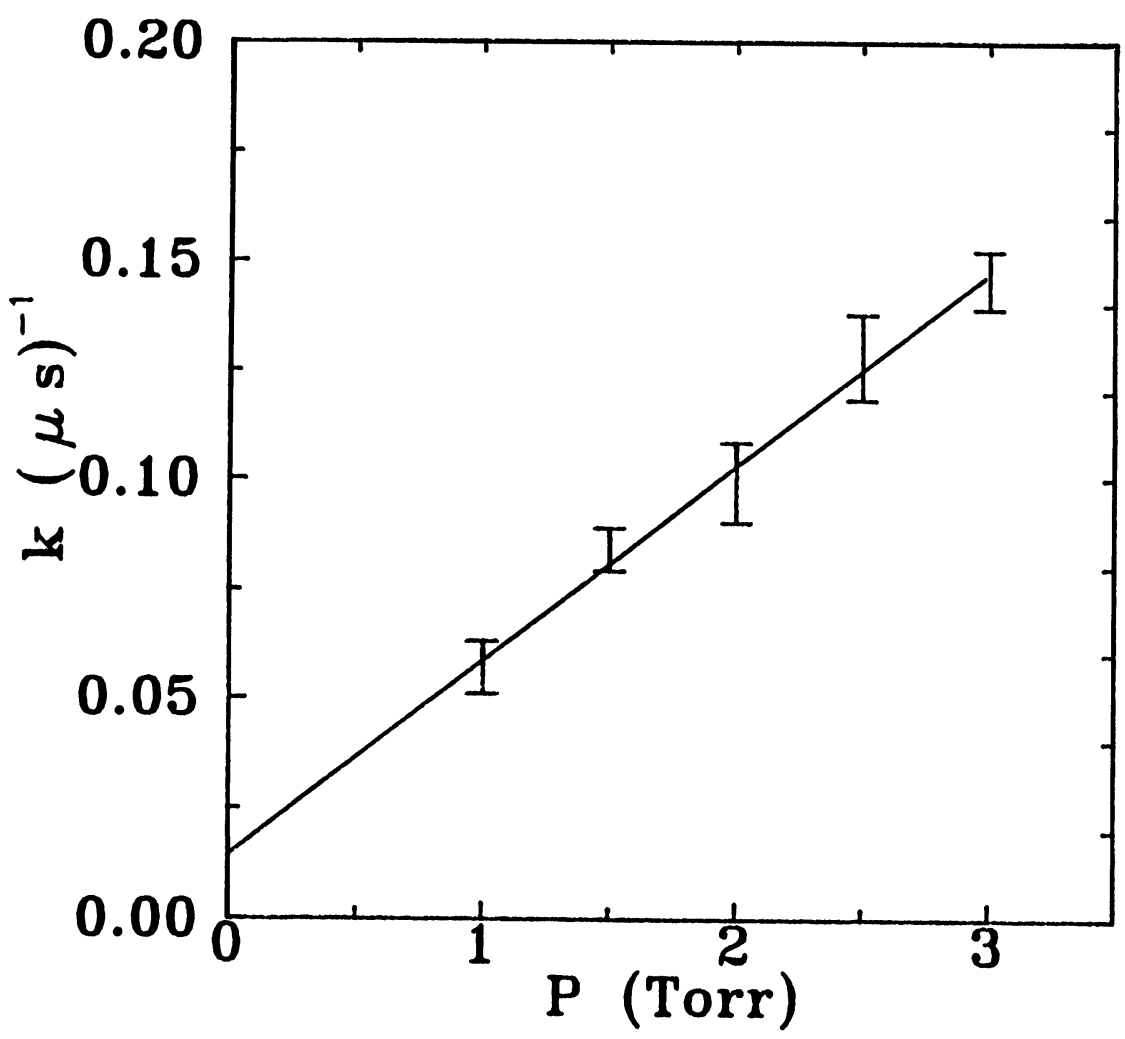

Figure 4 Pseud of first order rate constant as a function of $\mathrm{CH}_{3} \mathrm{OD}$ pressure. Error bars indicate the standard deviation of 8 measurements.

the available data for the $\mathrm{OH} /$ methanol reaction reveals that rate constants calculated in Table 1 are consistently higher than those obtained by other authors at room temperature. A recent analysis of the experimental data available for the $\mathrm{OH} / \mathrm{CH}_{3} \mathrm{OH}$ reaction has lead Atkinson to recommend the following expression for the rate constant of reaction (1) over the temperature range of $240-866 \mathrm{~K},{ }^{33}$

$$
\mathrm{k}_{1}(\mathrm{~T})=(6.39 \pm 0.6) \times 10^{-18} \mathrm{~T}^{2} \mathrm{e}^{(148 \pm 33) / \mathrm{T}} \mathrm{cm}^{3} \text { molecule }{ }^{-1} \mathrm{~s}^{-1}
$$

Table 1 Rate constants derived from the graphs of the pseudo-first order rate constant $\mathrm{k}$ as a function of pressure for the different isotopomers of methanol. ${ }^{(\mathrm{a})}$

\begin{tabular}{llll}
\hline & Reaction & $k / \mu s^{-1}$ Torr $^{-1}$ & $k_{\text {oH }} / 10^{-12} \mathrm{~cm}^{3}$ molecule $^{-1} \mathrm{~s}^{-1}$ \\
\hline$(1)$ & $\mathrm{CH}_{3} \mathrm{OH}+\mathrm{OH}$ & $0.058 \pm 0.004$ & $1.79 \pm 0.12$ \\
$(2)$ & $\mathrm{CD}_{3} \mathrm{OH}+\mathrm{OH}$ & $0.027 \pm 0.003$ & $0.83 \pm 0.09$ \\
$(3)$ & $\mathrm{CH}_{3} \mathrm{OD}+\mathrm{OD}$ & $0.055 \pm 0.003$ & $1.70 \pm 0.09$ \\
$(4)$ & $\mathrm{CD}_{3} \mathrm{OD}+\mathrm{OD}$ & $0.040 \pm 0.003$ & $1.23 \pm 0.09$ \\
\hline
\end{tabular}

(a) The rate constants, $\mathrm{k}_{\mathrm{OH}}$, were calculated by assuming a methanol bulk temperature of $298 \mathrm{~K}$. (See text). 
which yields $\mathrm{k}_{1}(298 \mathrm{~K})=9.32 \times 10^{-13} \mathrm{~cm}^{3}$ molecule $^{-1} \mathrm{~s}^{-1}$ with a combined uncertainty of $25 \%$ compared with $9.34 \times 10^{-13} \mathrm{~cm}^{3}$ molecule ${ }^{-1}$ obtained by Tully, ${ }^{22}$ and $10.1 \times$ $10^{-13} \mathrm{~cm}^{3}$ molecule ${ }^{-1}$ obtained by McCaulley. ${ }^{23}$ Our value for $\mathrm{k}_{1}$ is comparable to that expected for temperatures in the range of $449 \pm 40 \mathrm{~K}$, a temperature similar to that proposed by Guillory ${ }^{27}$ from the steady state rotational distribution, and should be compared with the value of $(1.69 \pm 0.04) \times 10^{-12} \mathrm{~cm}^{3}$ molecule ${ }^{-1} \mathrm{~s}^{-1}$ reported in Ref. 22. A similar consideration is valid for our rate constant for the $\mathrm{OH} / \mathrm{CD}_{3} \mathrm{OH}$ reaction, for which a value of $(9.20 \pm 0.04) \times 10^{-13} \mathrm{~cm}^{3}$ molecule ${ }^{-1} \mathrm{~s}^{-1}$ has been obtained at $\mathrm{T}=438.5 \mathrm{~K} .{ }^{22}$

The question of whether temperature equilibrium is achieved in the reaction zone of these experiments is complex. The $\mathrm{CO}_{2}$ laser pulse acts as a localized heating pulse creating a shock wave that proceeds outward from the focal region. Thus, the local conditions of our experiments are probably best represented in terms of temperature gradients. Furthermore, the geometry used in our experiments interrogates $\mathrm{OH}$ radicals produced along the cone of the $\mathrm{CO}_{2}$ focused laser radiation. Recent experiments reveal that the nascent temperature of transient species and the vibrational temperature of the parent molecule can be dramatically different in this cone of variable laser fluence ${ }^{34}$ The previous findings on the achievement of a steady state rotational population for the $\mathrm{OH}$ radical in this type of experiments suggest that our rate constants more likely reflect an average over the temperature profile of the area probed by the excimer laser.

The isotope effect observed in our experiments also provide valuable and relevant information on these reaction. For example, we find

$$
\left(\mathrm{k}_{1} / \mathrm{k}_{2}\right)=(2.15 \pm 0.13)
$$

which is identical to the value reported by Tully $e t a l^{22}$ at $293 \mathrm{~K}$, and which was shown to decrease very slowly with temperature below $600 \mathrm{~K}$. On the other hand, McCaulley $e t a^{23}$ have reported this ratio to be $(3.01 \pm 0.24)$ at room temperature. This isotope effect is a function of the branching ratio and of the actual isotope effect at the site of the hydrogen atom abstraction. Recent measurements of the rate constants for reactions of $\mathrm{OH}$ with alkanes support the idea that deuterium substitution only affects the rate constant for abstraction at the substitution site..$^{35}$ If reaction (1a) is assumed to account for approximately $80 \%$ of the total reaction, reaction (1a) can be estimated to exhibit $k_{H} / k_{D} \sim 3$. A much smaller isotope effect, if any, is observed upon comparison of reactions (1) and (3), where $\mathrm{OH}$ has been replaced by $\mathrm{OD},\left(\mathrm{k}_{1} / \mathrm{k}_{3}\right)=(1.05 \pm 0.08)$. The only other measurement for these reactions ${ }^{23}$ reports $\left(\mathrm{k}_{1} / \mathrm{k}_{3}\right)=(1.09 \pm 0.15)$ at $298 \mathrm{~K}$. In light of this agreement, the rate constant for reaction (4) seems unusually large and should be viewed with caution. It seems unlikely that this value reflects reaction of $\mathrm{OH}$ radicals (originating from $\mathrm{CD}_{3} \mathrm{OH}$ as the result of exchange at the walls of the cell) since the same value has been obtained over a period of time under similar cell conditioning procedures. Furthermore, the OD fluorescence is much stronger than that of $\mathrm{OH}$.

An extension of this work to assess the question of the temperature would ideally entail the measurement of these reactions under a wide variety of fluence conditions and under tailored $\mathrm{CO}_{2}$ laser pulses. Yet, the present technique can be useful to 
model reactions of $\mathrm{OH}$ with other substrates of atmospheric and combustion interest under non-equilibrium conditions.

\section{Acknowledgements}

The authors are especially thankful to the Laser Division of the IEAv for their technical support, and to the Brazilian Research Council (CNPq) and São Paulo Science Foundation (FAPESP) for general support.

\section{References}

1. C. K. Westbrook and F. L. Dryer, J. Combust. Sci. Technol. 2, 125 (1979).

2. T. S. Norton and F. L. Dryer, Int. J. Chem. Kinet. 24, 319 (1992).

3. P. H. Cribb, J. E. Dove and S. Yamazaki, Combust. Flame 88, 186 (1992).

4. R. Atkinson, Chem. Rev. 86, 69 (1986).

5. I. Messing, C. M. Sadowski and S. V. Filseth, Chem. Phys. Letters 46, 95 (1979).

6. P. W. Fairchild, G. P. Smith and D. P. Crosley, ACS Symp. Series 249, 239 (1984).

7. H. Reisler, M. Mangir and C. Wittig, Chem Phys. Letters 47, 49 (1980).

8. J. M. Riveros, P. C. Isolani and S. R. A. Leite, Chem. Phys. Letters 99, 442 (1983).

9. S. R. A. Leite P. C. Isolani and J. M. Riveros, Can. J. Chem. 62, 1380 (1984).

11. P. C. Isolani, H. V. Linnert and J. M. Riveros, J. F. G. Faigle, An. Acad Bras. Ci. 57, 522 (1985).

12. J. M. Riveros, Report on Elementary Reactions in the Combustion of Ethanol, Secretary of Industrial Technology of Brazil, (1988).

13. H. V. Linnert, Doctoral Thesis, University of São Paulo, (1989).

14. R. A. Copeland, J. B. Jeffries and D. R. Crosley, Chem. Phys. Letters 138, 425 (1987).

15. I. M. Campbell, D. F. McLaughlin and B. J. Handy, Chem. Phys. Letters 38, 362 (1976).

16. R. Overend and G. Paraskevopoulos, J. Phys. Chem. 82, 1329 (1978).

17. A. R. Ravishankara and D. D. Davis, J. Phys. Chem. 82, 2852 (1978).

18. J. Hägele, K. Lorenz, D. Rhasa and R. Zellner, Ber. Bunsenges Phys. Chem. 87, 1023, (1983).

19. U. Meier, H. H. Grotheer and Th. Just, Chem. Phys. Letters 106, 97 (1984).

20. P. G. Greenhill and B. V. O'Grady, Aust. J. Chem. 39, 1775 (1986).

21. T. J. Wallington and M. J. Kurylo, Int. J. Chem. Kinet. 19, 1015 (1987).

22. W. P. Hess and F. P. Tully, J. Phys. Chem 93, 1944 (1989).

23. J. A. McCaulley, N. Kelly, M. F. Golde and F. Kaufman, J. Phys. Chem., 93 (1989) 1014.

24. K. D. Asmus, H. Mockel and A. Henglein, J. Phys. Chem. 77, 1218 (1973).

25. G. H. Dieke and H. M. Crosswhite, J. Quant. Spectrosc. Radial. Transfer. 2 , 97 (1962).

26. M. A. A. Clyne, J. A. Coxon and A. R. W. Fat, J. Mol. Spectrosc. 14, 146 (1973).

27. S. E. Bialkowski and W. A. Guillory, J. Chem. Phys. 67, 2061 (1977).

28. S. E. Bialkowski and W. A. Guillory, J. Chem. Phys. 68, 3339 (1978).

29. R. Schmiedl, U. Meier and K. H. Welge, Chem. Phys. Letters 80, 495 (1981).

30. V. N. Bagratashvili, M. V. Kuzmin, R. R, Osmanov, F. N. Putilin and L. N. Vereshchagina, Chem. Phys. Letters 120, 211 (1985).

31. J. D. Lambert, Vibrational and rotational relaxation in gases, Clarendon Press, Oxford, Chapter 5 (1977).

32. F. P. Tully, Chem. Phys. Letters 143, 510 (1988).

33. R. Atkinson, J. Phys. Chem. Ref. Data, 19 (1989), Monograph 1.

34. W. Struße, J. Wollbrandt, M. Rossberg and E. Linke, Vibrational Energy Transfer Processes in the IR-Multiphoton Dissociation of $\mathrm{CF}_{2} \mathrm{HCl}$ and $\mathrm{CF}_{2} \mathrm{CI}_{2}$ at Higher Pressures, 2nd. Conference on Lasers in Chemistry, Trieste, Italy, November, 1993.

35. F. P. Tully, A. T. Droege, M. L. Koszykowski and C. F. Melius, J. Phys. Chem. 90, 691 (1986). 